\title{
Production Standards, Competition and Vertical Relationship
}

\begin{abstract}
This paper investigates the collective choice of production standards by farmer and processor groups within a vertical food supply chain, taking into account their competition behaviors. In a context in which raising standards cannot translate into a direct price premium to consumers, we develop a general model to analyze the strategic motive of using standards to limit supply and shift rents among farmers and processors in the vertical chain. We find that such a motive depends on farmers' cost structure, final demand characteristics, and processors' competition patterns. In particular, farmers prefer a stringent standard when the standard involves creating greater diseconomies of scale in production and when the demand for the final product is inelastic. However, processors only prefer a stringent standard in the presence of oligopsony competition.
\end{abstract}

Key words: Production standards, Vertical relationship, Imperfect competition, Technology choice

JEL Classification: L13, Q13 


\section{Introduction}

Private production standards have gained increasing importance as a mode of market governance for global agri-food chains in the last two decades (Henson and Humphrey 2009). They cover a wide range of production attributes and provide ways to reduce risk in the production chain (production, processing, and transport), certify the origin of food, control the environmental and social impacts of food production, and cope with individual responsibility concerns (Henson and Caswell 1999). Private standards complement public standards to the extent that they are often more stringent and are more specific and prescriptive, and to the extent that their development and implementation can involve wider participation and cooperation of different groups of stakeholders along the production chain (producers, processing firms, and retailers). In recent times, it has been documented that, in relation to private standards, there has been an increase in the number of collective production standards adopted either by producer/farmer organizations, retailer groups, or inter-professional groups involving farmers and food processing firms and retailing companies (Giraud-Heraud et al. 2012; Hayes, Lence, and Stoppa 2004; Hammoudi, Hoffmann, and Surry 2009). There can be little doubt that the development and adoption of these standards will have a deep impact on the individual behavior of different stakeholders, on their competition and coordination, and hence on the industry development of the whole food supply chain. As discussed in Gardner (2003) and McCluskey (2007), strategic motives for setting private standards can be an important factor that has driven the recent growth of both public and private food quality standards. The purpose of this paper is thus to investigate the strategic motives of the industry to collectively develop or adopt stringent production standards.

The implementation of standards is costly for the supply chain. Costs may arise when producers upgrade their production technology, increase their control or care during the production process, and apply for certification under the supervision of third-party agencies (See Henson and Heasman 1998; Antle 2001, etc. for a discussion on costs of food safety standards). Such costs should be compensated by the market so that firms have incentives 
to adopt these standards. However, in practice, it is not obvious that the implementation of costly standards generates higher benefits.

First, some of these standards are not directly communicated to consumers (Giraud-Heraud et al. 2012; Marette 2008). The development of standards is not motivated for the reason of product differentiation or market segmentation as it does not directly raise consumers' willingness to pay. For instance, at the downstream level, large companies or retailers jointly develop industry-wide standards that impose production requirements upon upstream producers. Examples are the Food Technical Standard developed by the British Retail Consortium (BRC), the International Food Standard (IFS), and the Global Good Agriculture Practice (GAP) standard. These standards are business-to-business (B2B) standards and are not directly communicated to consumers.

Second, for those standards that aim to segment the market, some of the product attributes may not bring about a higher willingness to pay amongst consumers. For example, the Geographical Indication (GI) labels (such as the Protected Designation of Origion (PDO) and the Protected Geographical Indication (PGI)) are developed by both producers and processors within a geographical area. In order to obtain the certification, producers have to comply with specific production requirements, which may raise their production costs substantively (Bouamra-Mechemache and Chaaban 2010). However, some evidence has shown the lack of a linkage between the GI price premiums and product quality. ${ }^{1}$

Therefore, when stakeholders along the vertical supply chain cannot directly benefit from an additional price premium in the final market by raising production standards, questions such as these arise naturally: Why do stakeholders still have incentives to impose stringent production standards? Who have incentives to do so, farmer organizations at the upstream level or processor/retailer groups at the downstream level, or both? How do stringent standards affect stackeholders' coordination?

In this paper, we are interested in analyzing the private incentives of each category of stakeholders in defining their production standard level. We focus particularly on the upstream 
farmers' production standards, which are elemental for achieving various product attributes (food safety, provenance, environment protection, animal welfare, etc). In this case, farmers will incur the cost of complying with the standard, but the stringency of standards may be defined either by farmer organizations or by large company groups at the processing or retailing levels. The level of standard will thus depend on who define the standards, which, in turn, will depend on how the standards affect the vertical coordination and the competition structure of these players at different levels of the supply chain.

Motivations for setting private standards have been studied extensively in the literature. While much work focuses on individual incentives in various aspects such as to differentiate products in response to public minimum quality standards (MQS) (see, e.g., Garella and Petrakis 2008; Crampes and Hollander 1995; Ronnen 1991), to provide information that affects consumers' perception of food quality and safety (Marette 2007, 2008), to protect firms' reputations against the loss of consumers' trust (Carriquiry and Babcock 2007; Winfree and McCluskey 2005), or to impose non-tariff trade barriers for producers in developing countries (Beghin and Bureau 2001; Henson and Humphrey 2009), the motives for creating collective private standards have received relatively less attention. Merel and Sexton (2011) analyze the standard choice by a PDO producer organization, where producer members behave competitively in quantity decisions. They argue that the decision about the standard depends on the interplay of two effects: a demand-enhancing effect, which shifts the demand curve outwards, and a supply-limiting effect, which restricts supply. As is well recognized in many studies (see, e.g., Merel 2009; Lence et al. 2007; Marette and Crespi 2003; Hayes, Lence, and Stoppa 2004; Marette, Crespi, and Schiavina 1999), the latter effect can be used strategically by the producer organization to raise the market price indirectly and hence mitigate the competition externality.

These studies, however, do not take into account the fact that producer organizations interact with processors or retailers along the vertical supply chain. In this context, standards may also be used as a strategic device to affect vertical coordination, and hence the distribu- 
tion of profits along the supply chain. In a recent article, von Schlippenbach and Teichmann (2012) analyze the individual incentive of retailers in choosing private quality standards. In the context in which standards bring about an additional price premium, they find that retailers may use standards to increase their bargaining position in the intermediate goods market. In contrast, Giraud-Heraud et al. (2012) argue that some standards, in particular joint private standards, aim neither to affect consumers' willingness to pay nor to increase the bargaining power of retailers, but rather are intended to reduce the risks of a drop in demand and liability when a food crisis occurs. They find that the stringency of standards will depend on the size of the coalition of retailers, who coordinate with upstream producers in the intermediate market through wholesale prices, rather than individual contracts.

These papers focus on the incentive of downstream firms to use standards to affect their coordination with upstream farmers. In many cases, however, the standards are developed by farmer associations or through negotiation between upstream and downstream groups. In this paper, we develop a general model to incorporate the decisions of different stakeholders along the supply chain, in which a producer organization and a processor/retailer group trade in the intermediate market. Following Giraud-Heraud et al. (2012), we analyze the situation in which a stringent standard does not generate a direct price increase in the final market, but affects farmers' production technologies and hence can be used as a way to shift farm production as well as final product supply. Thus, we focus on the "positive" supply-limiting effect for the two groups of stakeholders, respectively, and derive the condition under which the stringent standard will be adopted strategically by farmers or processors to raise the industry surplus or to affect the partition of the industry surplus.

The choice of standards depends on the structure of competition. Chen and Lent (1992) analyze the effect of a downward shift in the supply of a farm product in the presence of oligopsony power of processors. They find that the supply shift will increase the farm price as well as the processors' profits in the case of perfect competition, while it has an ambiguous effect under imperfect competition. Similar results are found in Hamilton and 
Sunding (1997) in the case of free entry of heterogeneous processors. However, these papers assume that processors are price-takers in the final product market, which is often not the case in the agri-food industry. In the presence of both oligopoly and oligopsony competition, Hamilton and Sunding (1998) investigate the effect of a downward supply shift due to public investment. Our analysis complements these studies by introducing production standards as a device to restrict supply at both the upstream and downstream levels and identifying the market structure and technology that allow farmers or processors to benefit from a costly increase in a production standard.

Our results show that the adoption of stringent standards depends crucially on two aspects: the type of standards that may shift farm supply in different ways, and the type of competition among processors that affects profit margins and the partition of profits among different participants in the production chain. In particular, we find that farmers prefer a stringent standard when the technology requirements make the production involve greater diseconomies of scale and when the final product demand is inelastic. However, it is so for processors only in the presence of oligopsony competition. To our knowledge, this is the first work investigating the conflicting incentives of adopting standards by different players along the food supply chain. Accordingly, it can yield further insights into implications of production standard regulations, in particular, with regard to the question of which group in the supply chain benefits if the government intends to promote a particular standard.

The paper is structured as follows. Section 2 provides a description of voluntary private standards, which differ according to the initiatives. Section 3 presents a model with general cost and demand functions. Section 4 analyzes the adoption of standards in the presence of perfect competition. Section 5 introduces imperfect competition and disentangles the effects in the oligopoly and oligopsony cases, respectively. Section 6 illustrates and discusses the results and Section 7 presents the main conclusions. 


\section{Voluntary private standards}

Since the 1990s, a growing number of food standards have been developed around the world in order to improve food product quality and production processes (See, e.g., Bredahl et al. 2001 for a typology of standards and Hatanaka, Bain, and Busch 2005 for an overview of standard evolution in the world). These standards are very diverse and differ depending on who initiates the standard and who adopts it, and according to the parameters of the agrifood system (Henson and Humphrey 2009). Table 1 provides some examples of standards and classifies the standards according to who develops the standards, including farming, processing, and retailing along the food supply chain.

At the upstream level, some farmers coordinate themselves through setting their own production standard (NatureLand, Organic Valley, among others). The number of producer groups has increased in recent years. They take the form of producer associations and cooperatives, in which members adhere voluntarily to specified production requirements (with respect to feeding, breeds, and animal welfare standards, for instance). These kinds of organizations may be a way to improve farmers' bargaining power with respect to large companies or retailers.

In parallel, a countermovement occurs at the downstream level. With increasing concerns about food safety, in particular, food contamination since the 1990s (for example, Salmonella, E. coli and the Bovine Spongiform Encephalopathy (BSE)), large companies (both at the processing and the retailing levels) are becoming stringent about the products of upstream suppliers (cf. Fulponi 2006). Production requirements have been transferred to the upstream stages of the supply chain in order to ensure that the production process meets the desired attributes, such as food safety, environment protection, and animal welfare (e.g., Nestlé Alete). Actually, retailers are playing a key role in governing the food system through the development of retailers' own standards (e.g., Nature's Choice of Tesco, Flière de Qualité of Carrefour). Private standards are one of the tools used by retailers to improve or maintain 
a reputation asset. They are also a way for retailers to comply with legislative requirements and protect themselves against legal action if a food safety incident does occur.

In addition to individual standards, collective initiatives have also emerged among major retailers and large food firms (e.g., EurepGap/GlobalGap, GFSI). These initiatives mostly apply to fresh products and aim to create a food safety assurance scheme. However, they are also now extended to other food product categories (meat, dairy, etc.) and other food characteristics (use of pesticides, environment protection, animal welfare, etc.). The production requirements are mainly imposed at the procurement stage. Hence, procurement firms need to comply with a given standard in order to find market access for their products (see, e.g., Manning, Baines, and Chadd 2007 in the case of the UK poultry meat market). These standards are B2B standards, and hence are not directly communicated to consumers (Hatanaka, Bain, and Busch 2005; Giraud-Heraud et al. 2012). Retailers may benefit from a highly concentrated market that allows them to use their position to exercise buying power at the expense of upstream firms when they are negotiating with such firms and hence reduce their procurement costs.

Some hybrid forms of standard initiatives also exist. The different parties in the supply chain are involved in the definition of the product specification (e.g., the Red Tractor scheme and the Canadian Cattlemen's Association). In this case, vertical coordination among the different stakeholders of the supply chain is necessary for the choice of standards. A particular form of collective initiatives are regional or traditional quality assurance systems such as the PDO in Europe or Label Rouge in France. They include all initiatives related to regional or local production. The production specifications are set by an association of all actors involved in the supply chain (including both farmers and processors, for instance). 


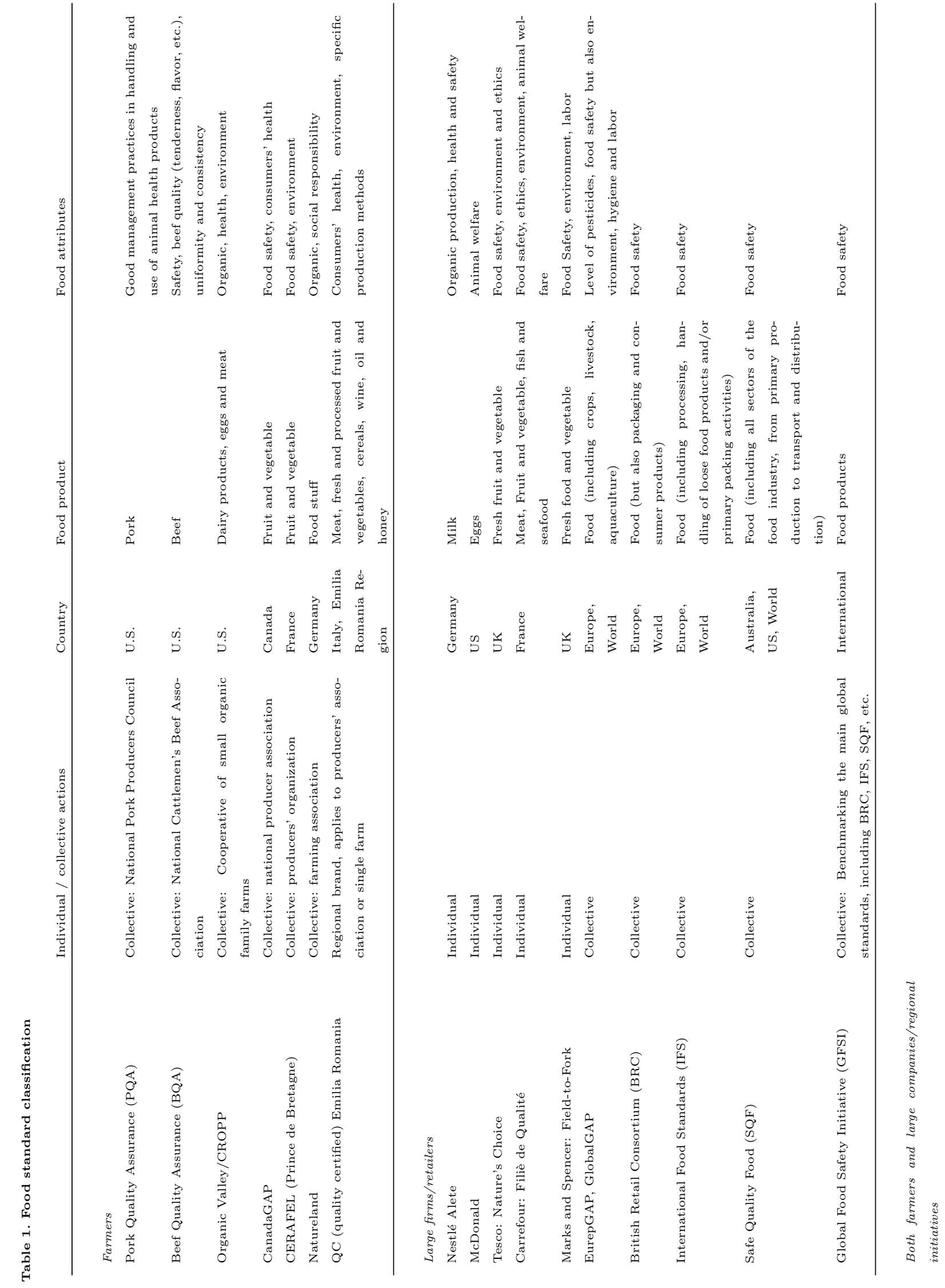




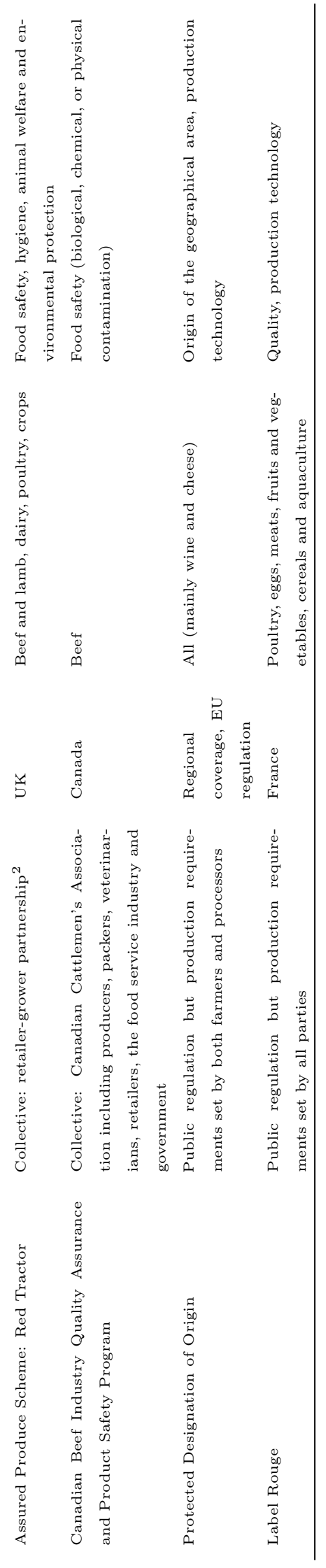




\section{Model}

We consider an agri-food supply chain in which $n$ identical farmers supply an agricultural input to $m$ identical food processors. ${ }^{3}{ }^{4}$ Farmers have to conform to a production standard, which defines the production requirements in terms of, for example, food safety, environment protection, animal welfare, etc. We denote by $\beta$ the stringency of the production standard, where $\beta \in[0,+\infty)$ and 0 corresponds to the level of MQS stipulated by the public authority. The standard is chosen at a collective level. The stringency can be defined either by the upstream farmers in a producer organization or by the group of processors, or jointly by both parties in the supply chain (cf. Section 2).

We assume that the standards are not directly visible to consumers. For instance, as emphasized in Section 2, B2B standards are often not communicated to consumers. Moreover, when standards are communicated through labels, the labels inform consumers about non-observable characteristics such that consumers know the general characteristics of the good but not the exact production technology, as it is costly to obtain precise and specific information about the product (Carriquiry and Babcock 2007; Marette 2008). In this case, our assumption implies that the label enhances the demand but that a change in the level of the standard does not change the demand, i.e., the stringency of the production requirement does not affect the consumers' willingness to pay. Hence, the inverse demand for the final

product can be written as $p(X)$, where $X$ is the demand quantity and $\frac{\partial p}{\partial X}<0 .{ }^{5}$

The production of the agricultural input depends on the production requirement. We denote by $c(q, \beta)$ the farmer's production cost, where $q$ is the quantity of production and $c_{q}(q, \beta)>0$ and $c_{q q}(q, \beta)>0$. The total cost of production is increasing with the stringency of the standard, $c_{\beta}(q, \beta)>0$. For generality of analysis, we do not specify the impact of a standard on the marginal cost at this point. In Section 6, we will discuss the choice of standards, which affects the production technology in different ways; in particular, we will discuss the case in which the standard induces an upward rotation of the supply curve. 
Following Giraud-Heraud et al. (2012), we assume that the transaction between farmers and processors is realized through an intermediate market. In this market, farmers sell their agricultural input to processors given the procurement price offered by the processors. Denoting by $w$ the price of the input, the profit for farmers is thus:

$$
\text { (1) } \quad \pi^{f}=w q-c(q, \beta)
$$

The farmers' supply decisions depend on their competition behaviors. Providing that farmers are atomic and the processing industry is concentrated, we assume that farmers are pricetakers of $w$. Hence, a farmer will produce so as to equalize the raw product price to its marginal cost, i.e., $w=c_{q}(q, \beta)$. We denote by $Q$ the total quantity of raw material supply. By symmetric assumption, $Q=n q$, which gives the inverse supply function for the aggregate input supply:

$$
\text { (2) } \quad w=c_{q}\left(\frac{Q}{n}, \beta\right)
$$

Processors use the agricultural input to produce a homogeneous final product. We assume a fixed proportion technology so that the production of one unit of the final product requires the use of one unit of raw input. For simplicity, we assume that no other costs are required, except for the cost of purchasing the raw input. To focus on the standards that target the farmers' production, we assume that the production standard affects only farmers' production costs and will not generate a direct cost at the processing level. For instance, Bredahl et al. (2001) argue that the Farm Assured British Beef and Lamb standard (FABBL, adopted by the Red Tractor group) only affects the supply level of the food supply chain and the detailed requirements of the standards are not publicly available. They also argue that some standards implemented in the US (the National Cattlemen's Beef Association's Beef Quality Assurance (BQA) and the National Pork Producers Council Pork Quality Assurance (PQA), among others) "tend to be limited to on-farm quality assurance, rather than providing assurance throughout the supply chain". 
Denoting by $x_{i}$ the quantity of the final product produced by processor $i(i=1,2, \ldots, m)$, the profit for processor $i$ is given by:

(3) $\pi_{i}^{p}=(p(X)-w) x_{i}$.

Processors simultaneously decide how much to sell in the downstream market and buy a quantity of input according to their downstream production decision. The market for the agricultural input then clears through the balance of supply and demand.

We focus on how competition among processors would affect the incentives of farmers and processors in choosing a stringent production standard. As a benchmark, we first analyze the standard choice in the case of perfect competition. We then investigate the case of imperfect competition, in which we distinguish the cases in which processors have oligopoly and oligopsony power, respectively.

\section{Benchmark-Perfect competition}

To investigate the choice of the standard by farmers and/or processors under perfect competition, we first derive the impact of a standard on the equilibrium quantity and on the final market and input prices. This allows us to derive the effect of a standard on farmers' profit and analyze the incentives for the producer organization to implement a stringent standard.

\section{Effect of the standard on quantities}

Under perfect competition, processors earn zero profit and the equilibrium final market price is equal to the procurement price, and hence to the farmers' marginal cost (cf. equation (2)). Taking into account the market-clearing condition, $X=Q$, we have:

$$
p(X)=w=c_{q}\left(\frac{X}{n}, \beta\right) .
$$

The impact of the production standard $\beta$ on the market equilibrium quantity $X$ is thus derived as:

$$
\frac{d X}{d \beta}=\frac{c_{q \beta}}{p^{\prime}-c_{q q} / n}=-\frac{p}{X} \frac{\varepsilon_{d} \varepsilon_{s}}{\varepsilon_{d}+\varepsilon_{s}} c_{q \beta}
$$


where $\varepsilon_{d}=-\frac{p(X)}{X p^{\prime}}$ and $\varepsilon_{s}=\frac{w}{\frac{\partial w}{\partial X} X}=\frac{c_{q} n}{c_{q q} X}$ represent, respectively, the elasticity of demand for the final product and the elasticity of aggregate input supply.

The production standard will affect the equilibrium quantity only if $c_{q \beta} \neq 0$, that is, if it changes the variable costs. If an increase in the production standard affects only the farmers' fixed costs but not their variable costs, the standard will have no impact on quantity. ${ }^{6}$ In general, variable costs increase with the stringency of the standard. For instance, to raise the standard, specific inputs or techniques are required, which generate an increase in the production cost of each unit. ${ }^{7}$ In the remainder of the paper, we focus on the cases in which $c_{q \beta}>0$ so that the equilibrium quantity decreases as the production requirement becomes more stringent, i.e., $\frac{d X}{d \beta}<0$.

The impact of $\beta$ on the final market price is derived as:

(6) $\frac{d p(X)}{d \beta}=p^{\prime} \frac{d X}{d \beta}=c_{q \beta} /\left(1+\frac{\varepsilon_{d}}{\varepsilon_{s}}\right)>0$.

Thus, under perfect competition, an increase in $\beta$ will have a positive impact on the final market price as well as on the input price at the equilibrium. In our setting, the increase in the price is not a result of a higher willingness to pay of consumers associated with a stringent standard, as the standard is not visible to consumers. It is rather linked to the cost effect, which leads to a decrease in quantity, and hence an increase in price. Other things being equal, this effect is large when the effect of $\beta$ on marginal cost $c_{q \beta}$ is large, and/or the supply elasticity for the input is large relative to the demand elasticity for the final product.

\section{Effect on profit}

The final decision on the standard level depends on how the effect on quantity affects the profits of farmers and processors. Under perfect competition, processors are price-takers for both the final product and the input prices. In this situation, their equilibrium profits are zero and hence independent of the standard level. Therefore, the choice of production requirement depends on the farmers' decision. 
If the production standard is decided by the producer organization, it will maximize the total profit for farmers. The impact of $\beta$ on the total farm profit can be derived using the farmers' profit condition (1), their supply function (2), and the market equilibrium condition (4):

(7) $\frac{d n \pi^{f}}{d \beta}=-n c_{\beta}+X \frac{d w}{d \beta}$.

On the one hand, $\beta$ will increase production costs, which tends to reduce the profit. On the other hand, the input price increases with $\beta$ (see equation (6)). The outcome of the trade-off between these two effects depends on the market characteristics as well as how the standard affects the farmers' cost structure. Formally, the impact of $\beta$ on the total farm profit can be rewritten as:

$$
\frac{d n \pi^{f}}{d \beta}=X c_{q \beta}\left(-\frac{1}{\eta}+\frac{1}{1+\frac{\varepsilon_{d}}{\varepsilon_{s}}}\right)
$$

where $\eta=\frac{c_{q \beta}}{c_{\beta} / q}$, measures the (partial) effect of the standard on the farmers' marginal cost relative to the effect on their average cost. A higher level of $\eta$ means that $\beta$ will increase the input price $w$ (which is equal to the marginal cost) more than the average cost.

From condition (8), the producer organization will choose a stringent standard $\left(\frac{d n \pi^{f}}{d \beta}>0\right)$ if and only if the following inequality holds:

$$
\text { (9) } \quad \eta>1+\frac{\varepsilon_{d}}{\varepsilon_{s}}
$$

Therefore, for a given level of diseconomies of scale, farmers have a collective incentive to choose a more stringent standard $(\beta>0)$ if the demand for the final product is inelastic and the supply of the input is elastic. This is due to the fact that the positive effect of $\beta$ on farmers' profit stems from an increase in the procurement price through a reduction in quantity (see equation (6)). At the equilibrium point, if the aggregate supply is elastic, a higher level of the standard will induce a larger decrease in quantity, which, in turn, will lead to a larger increase in the price if the demand is inelastic. 
Thus, condition (8) identifies the similar 'positive' supply-limiting effect, as is analyzed in Merel and Sexton (2011), but in a setting with more general demand and cost functions. ${ }^{8}$ However, this effect will not always be positive when the standard becomes more and more stringent. ${ }^{9}$ Hence, farmers will not choose an unlimited level of stringency for the standard, but the equilibrium level will still be more stringent than the public MQS level (which is 0 by assumption), providing that condition (8) holds at 0 (i.e., $\left.\frac{d n \pi^{f}}{d \beta}\right|_{\beta=0}>0$ ).

Figure 1 illustrates the case of linear demand and supply functions, where an increase in the standard leads to an upward rotation in the supply curve.

Figure 1 is inserted here.

For the standard increasing from $\beta_{1}$ to $\beta_{2}$, the equilibrium quantity is reduced from $X\left(\beta_{1}\right)$ to $X\left(\beta_{2}\right)$, and the price increases from $p\left(X\left(\beta_{1}\right)\right)$ to $p\left(X\left(\beta_{2}\right)\right)$. The total farm profit changes from the solid line triangle $\left(n \pi^{f}\left(\beta_{1}\right)\right)$ to the dashed line triangle $\left(n \pi^{f}\left(\beta_{2}\right)\right)$. It can be seen that when the demand is relatively elastic (figure 1a), the total farm profit may not be increased with $\beta$, while it is increased when the demand is inelastic (figure $1 b$ ).

To conclude, in a perfectly competitive market, the producer organization may have an incentive to implement a stringent standard even if the standard does not generate a market premium. This will be the case when the standard introduces greater diseconomies of scale in production and when the market is characterized by a relatively inelastic demand for the final product and a relatively elastic supply for the agricultural product. In the next section, we will analyze how this incentive changes under imperfect competition among processing firms.

\section{Imperfect competition}

In this section, we analyze how imperfect competition will affect the results obtained for the perfect competition benchmark. We first derive the general conditions, under which farmers and/or processors choose a stringent standard. We then disentangle the effects of oligopoly 
and oligopsony power of the processors to better address the impact of market power under different competition frameworks.

\section{General results}

We assume that processors compete à la Cournot in both the final product and the input procurement markets. A processor will choose the production quantity, $x_{i}$, anticipating the impact of this decision on the prices of both the final product and the input. We denote by $X_{-i}=\Sigma_{j \neq i} x_{j}$ the total quantity produced by other processors except producer $i$. Given the market-clearing condition $Q=X=x_{i}+X_{-i}$ and the farmers' supply condition (2), the profitmaximizing program of processor $i$ can be written as:

$$
\max _{x_{i}} \pi_{i}^{p}=\left(p\left(x_{i}+X_{-i}\right)-c_{q}\left(\frac{x_{i}+X_{-i}}{n}, \beta\right)\right) x_{i} .
$$

By symmetry, we have $x_{i}=\frac{X}{m}$ for $i=1,2, \ldots m$ in equilibrium. Hence, the first-order condition of each processor's maximization program can be written as:

$$
p(X)-c_{q}\left(\frac{X}{n}, \beta\right)=-\frac{X}{m} p^{\prime}(X)+\frac{X}{m} \frac{c_{q q}\left(\frac{X}{n}, \beta\right)}{n} .
$$

To ensure the existence and uniqueness of the solution, we assume that the second-order condition satisfies:

$$
S O C=\frac{m+1}{m}\left(p^{\prime}(X)-\frac{c_{q q}\left(\frac{X}{n}, \beta\right)}{n}\right)+\frac{X}{m}\left(p^{\prime \prime}(X)-\frac{c_{q q q}\left(\frac{X}{n}, \beta\right)}{n^{2}}\right)<0 .
$$

This condition holds for not-too-convex demand functions and not-too-concave supply functions.

From condition (10), the equilibrium industry quantity is affected by the market power of processors. Noting that $w=c_{q}\left(\frac{X}{n}, \beta\right)$, the processor's price-cost margin $\left(p(X)-c_{q}\left(\frac{X}{n}, \beta\right)\right)$ is determined by two effects, an oligopoly power effect $\left(-\frac{X}{m} p^{\prime}(X)\right)$ and an oligopsony power effect on input procurement $\left(\frac{X}{m} \frac{c_{q q}\left(\frac{X}{n}, \beta\right)}{n}=\frac{X}{m} \frac{\partial w}{\partial X}\right)$. Other things being equal, the higher the level of concentration in the processing industry (the smaller is $m$ ), the larger the market power of processors and hence the larger the mark-up for the processing industry. ${ }^{10}$ 
The level of the standard will affect the equilibrium quantity. Using the implicit function theorem, the effect of $\beta$ on quantity can be derived from equation (10):

(12) $\frac{d X}{d \beta}=\frac{c_{q \beta}+\frac{q}{m} c_{q q \beta}}{S O C}$.

Given (11) and (12), the impact of $\beta$ on $X$ depends on the number of processors in the industry $(m)$, and on how the standard affects farmers' cost structures.

The impact of $\beta$ on the procurement price $w$ is derived from condition (2):

$$
\frac{d w}{d \beta}=c_{q \beta}+\frac{c_{q q}}{n} \frac{d X}{d \beta}
$$

Using equation (7) and substituting $\frac{d w}{d \beta}$ with its expression in (13), the impact of the standard on the total farmers' profit can be rewritten:

$$
\frac{d n \pi^{f}}{d \beta}=\underbrace{X c_{q \beta}}_{+}+\underbrace{X \frac{c_{q q}}{n} \frac{d X}{d \beta}}_{-} \underbrace{-n c_{\beta}}_{-} .
$$

Therefore, the total impact on the farmers' profit depends on the relative magnitude of three effects: the direct effect on the procurement price $\left(X c_{q \beta}=X \frac{\partial w}{\partial \beta}\right)$, which shifts upward the farmers' supply curve and may affect negatively farmers' profits, the indirect effect linked to the quantity reduction $\left(X \frac{c_{q q}}{n} \frac{d X}{d \beta}\right)$, which is negative and may or may not balance out the former effect,, and the direct effect, which increases production cost $\left(-n c_{\beta}\right)$. Note that this general condition holds for all types of competition. The impact of imperfect competition hinges on the ability of a standard to reduce the quantity $\left(\frac{d X}{d \beta}\right)$, which depends on the number of processors. As a result, the magnitude of the quantity restriction can be lower or higher than in the perfect competition case such that a stringent standard is more or less likely to be chosen by farmers depending on the imperfect competition patterns.

The impact of a standard on the total processors' profit is derived as:

$$
\frac{d m \pi^{p}}{d \beta}=\underbrace{-X c_{q \beta}}_{-}+\underbrace{\frac{\partial \pi^{p}}{\partial X} \frac{d X}{d \beta}}_{+} .
$$


The standard will affect profit directly through its impact on the procurement cost $\left(-X c_{q \beta}=\right.$ $\left.-X \frac{\partial w}{\partial \beta}\right)$ and indirectly by changing the quantity $\left(\frac{\partial \pi^{p}}{\partial X} \frac{d X}{d \beta}\right)$. If there is only one processor acting as a monopoly both in the upstream and downstream markets, the indirect effect vanishes $\left(\frac{\partial \pi^{p}}{\partial X}=0\right)$ and the processor will always prefer the lowest standard $(\beta=0)$. However, if more than one firm is present in the markets, the indirect effect is positive $\left(\frac{\partial \pi^{p}}{\partial X}<0\right)$. Processors may thus have the incentive to set a higher standard so as to constrain the quantity level and restore the monopoly and monopsony power. Indeed, from a processor's point of view, the production standard can serve as a device to correct the quantity distortion due to the intensity of competition among processors. This indirect effect may be mitigated by the direct effect on procurement cost. As a result, a stringent standard is more or less likely to be chosen by processors depending on the imperfect competition patterns.

Note that the price-cost margin for processors can be derived as:

$$
\frac{d(p(x)-w)}{d \beta}=p^{\prime} \frac{d X}{d \beta}-\frac{d w}{d \beta}=p^{\prime} \frac{d X}{d \beta}-\left(c_{q \beta}+\frac{c_{q q}}{n} \frac{d X}{d \beta}\right)
$$

Hence, the standard can be used both as a device to maximize the total rent of the supply chain through the restriction of quantity $\left(p^{\prime} \frac{d X}{d \beta}\right)$ and to share the unit profit between farmers and processors through the impact on the procurement price $\left(\frac{d w}{d \beta}\right)$. The latter impact also depends on the quantity restriction magnitude, which is determined by the competition pattern.

The above analysis suggests that either processors and/or farmers may choose a stringent standard. Moreover, they may have conflicting interests when deciding the level of the standard. This can be illustrated in figure 2 .

Figure 2 is inserted here.

Figure 2 compares the equilibrium for two standard levels $\left(\beta_{1}<\beta_{2}\right)$. The equilibrium is given by the intersection between the marginal revenue curve $\left(\operatorname{Rm}(X)=p(X)+\frac{X}{m} p^{\prime}(X)\right)$ and the perceived marginal cost curve for processors $\left(C m(X)=c_{q}\left(\frac{X}{n}, \beta\right)+\frac{X}{m} \frac{c_{q q}\left(\frac{X}{n}, \beta\right)}{n}\right)$. The equilibrium profit for farmers and processors are respectively represented by the triangular 
and rectangular areas. When $\beta$ increases, the equilibrium quantity decreases from $X\left(\beta_{1}\right)$ to $X\left(\beta_{2}\right)$. Following the decrease in the equilibrium quantity as well as the changes in the farmers' supply function, the equilibrium prices of both the agricultural input and the final product increase. It can be seen from figure 2 that farmers' benefit from the change in the procurement price dominates the negative effect of the quantity restriction. However, for processors, the increase in the final commodity price is offset by the increase in the procurement cost.

\section{Oligopoly and oligopsony competition}

To investigate how competition patterns will affect the incentive of farmers and/or processors to choose a stringent standard, we distinguish two cases: oligopoly, where the processors are price-takers of the procurement price, and oligopsony, in which they are price-takers in the final market.

Oligopoly In this case, the first-order condition (10) can be expressed as:

$$
p(X)-c_{q}=-\frac{X}{m} p^{\prime}(X)
$$

Using the implicit function theorem, we derive the impact of $\beta$ on the industry output:

$$
\text { (18) } \frac{d X}{d \beta}=\frac{c_{q \beta}}{p^{\prime}-\frac{c_{q q}}{n}+\underbrace{\frac{1}{m}\left(p^{\prime}+X p^{\prime \prime}\right)}_{-}} \text {. }
$$

Other things being equal, the industry output is less affected by the production standard under oligopoly compared with the perfect competition benchmark. This can be seen from equation (18), where an extra negative term $\frac{1}{m}\left(p^{\prime}+X p^{\prime \prime}\right)$ in the denominator reduces the absolute effect of $\beta$ on $X$ (i.e., $\left|\frac{d X}{d \beta}\right|_{\text {oligopoly }}<\left|\frac{d X}{d \beta}\right|_{\text {perfect competition }) .}{ }^{11}$ The intuition stems from the fact that, with oligopoly, firms choose their quantity such that marginal revenue equals marginal cost, i.e., the procurement price. Given that the marginal revenue curve is 
less elastic than the demand curve, for the same increase in the marginal cost induced by $\beta$, the cut in equilibrium quantity is lower under oligopoly than under perfect competition.

Oligopsony In this case, the first-order condition (10) can be expressed as:

$$
p(X)-c_{q}=\frac{X}{m} \frac{c_{q q}}{n} .
$$

The impact of $\beta$ on industry output is derived as:

$$
\frac{d X}{d \beta}=\frac{c_{q \beta}+\frac{\overbrace{q}}{m} c_{q q \beta}}{p^{\prime}-\frac{c_{q q}}{n} \underbrace{\frac{1}{m n}\left(c_{q q}+q c_{q q q}\right)}_{-}} .
$$

The quantity restriction effect under oligopsony differs from the perfect competition case in two aspects. On the one hand, similarly to the oligopoly case, the industry output under oligopsony tends to be less affected by the production standard compared with the perfect competition benchmark due to the presence of the negative term $-\frac{1}{m n}\left(c_{q q}+q c_{q q q}\right){ }^{12}$ This can be explained by the fact that, under oligopsony, firms choose their quantity such that price equals the perceived marginal cost $\left(c_{q}+\frac{X}{m} \frac{c_{q q}}{n}\right)$. Given that the perceived marginal cost curve is less elastic than the supply curve, for the same increase in the marginal cost induced by $\beta$, the cut in equilibrium quantity is lower under oligopsony than under perfect competition. On the other hand, the perceived marginal cost can also be modified by the stringency of the standard $\left(\frac{q}{m} c_{q q \beta}\right)$, depending on the technology requirement. For instance, if the technology induces an upward rotation of the supply curve, the quantity restriction effect will be reinforced. As a result, the overall impact of the standard on the equilibrium quantity and on farmers' and processors' profits will depend on the supply curve rotation, the degree of oligopsony power, and the market characteristics. This point will be discussed in Section 6. 


\section{Choice of a stringent standard}

In this section, we stress the conditions under which farmers and/or processors may have incentives to choose a stringent standard. We investigate how their incentives are influenced by the interaction between the processors' competition behavior and the demand and supply characteristics. For this, we derive the impact of $\beta$ on profits of farmers and processors as a function of the demand and supply elasticities and the technology parameters. We define $\mu=\frac{c_{q q \beta}}{c_{q \beta} / q}$, which reflects the impact of the standard on the rotation of the supply curve, and $V_{d}=-\frac{p^{\prime \prime} X}{p^{\prime}}$ and $V_{s}=\frac{c_{q q q}}{c_{q q} / q}$, the convexities of the demand and aggregate supply functions, respectively. The impact of $\beta$ on farmers' and processors' profits under different competition patterns is summarized in table 2 .

Table 2 is inserted here.

Under pure oligopoly, the conditions under which farmers and processors prefer a stringent standard are derived in the second column of table 2. As for farmers, the condition depends on the degree of processors' competition (measured by $m$ ) as well as the demand and supply characteristics. As in the perfect competition case, for a given level of diseconomies of scale $(\eta)$, it is more likely that farmers will choose a higher standard under oligopoly if the demand of the final product is inelastic and the supply of the input is elastic. The effect of oligopoly power can be seen from a reduction of $m$. The second term on the right-hand side of the farmers' profit condition increases with $m \cdot{ }^{13}$ Thus, the inequality will be more relaxed if processors have a higher degree of oligopoly power. As a result, it is more likely for farmers to choose a higher $\beta$ under oligopoly competition than under perfect competition among processors.

In contrast, processors will always prefer the lowest standard $(\beta=0)$. This can be seen by investigating the effect of the standard on the price-cost margin. From equations (16) and (18), we derive:

(21) $\frac{d(p-w)}{d \beta}=-c_{q \beta} \frac{p^{\prime}+X p^{\prime \prime}}{(m+1) p^{\prime}+X p^{\prime \prime}-\frac{m}{n} c_{q q}}<0$. 
This impact is negative provided that the second-order condition of the processors' profit maximization is negative. Given that the total processors' profit can be decomposed into the price-cost margin times the quantity and that the standard reduces the quantity level, the impact of the standard on the total processors' profit is unambiguously negative. Hence, processors will always have an incentive to choose the lowest standard if they only have market power over consumers but no power over farmers.

The above analysis suggests that there may be a conflict of interest between farmers and processors in deciding the production standard in the pure oligopoly case. In particular, processors prefers the minimum standard level, whereas farmers tend to choose a more stringent requirement. Therefore, under oligopoly, a stringent standard may be used by farmers as a rent-shifting device to get a larger share of vertical profit. However, this is to the detriment of the benefit of processors.

The impact of the standard under pure oligopsony is presented in the last column of table 2. The incentive of farmers to impose a stringent standard depends on the technology parameters $\eta$ (the impact of the standard on farmers' marginal cost relative to the effect on the average cost) and $\mu$ (the impact of the standard on the rotation of the supply curve) as well as the demand and supply characteristics. As both $\eta$ and $\mu$ are dependant upon how the standard modifies the technology, it is difficult to assess the impact of these parameters on the condition. Note that the second term on the right-hand side of the farmers' profit condition increases with $\mu$ and the larger is $\mu$, the more the supply curve will be rotated upward by the standard. It may be more likely that farmers choose a stringent standard if the rotation effect is not too large.

Investigating the condition for processors, we find that the right-hand side term is an increasing function of $\mu$. Hence, under pure oligopsony, processors are more likely to impose a stringent standard upon farmers if the standard rotation effect is larger (larger $\mu$ ). As a result, there may be conflicting interests between farmers and processors in choosing the level of the standard under oligopsony competition. Indeed, the larger the rotation effect 
(the larger is $\mu$ ), the more likely it is that processors will choose a higher standard, while farmers will prefer a lower one.

The degree of processors' oligopsony power also affects their incentive to set a stringent standard. It can be verified easily that the right-hand side term in the processors' profit condition is decreasing with $m$. Hence, the more power processors can exert over farmers, the less likely it is that these processors will impose a stringent standard upon farmers.

To conclude, it is possible for processors to choose a stringent standard only when they have oligopsony power. Otherwise, they will always prefer the lowest standard. On the contrary, farmers are more likely to choose a stringent standard because they may capture some rents by choosing a higher $\beta$. This is particularly true when farmers can define technological requirements that introduce greater diseconomies of scale in production. Thus, farmers and processors may have conflicting interests in choosing production standards in all cases. The ultimate level of a standard depends on which party initiates the standard. In the case where they jointly develop the production requirement, the level of the standard will be the result of negotiation between these two parties, depending on their relative bargaining power.

\section{Illustration and discussion}

The above analysis shows that the market characteristics and competition patterns play a determining role in the choice of standards. In this section, we first illustrate the choice of standard by farmers and processors by specifying the demand and cost functions. We then discuss more generally how our results can be applied to the agri-food sector.

As an illustration, we examine the choice of standard using a linear demand function $p(X)=a-b X$ and a quadratic cost function $c(q, \beta)=\frac{\beta}{2} q^{2}$. Such a cost function implies that a stringent production requirement can generate an increase in the marginal cost that is higher for a larger production quantity, i.e., $c_{q q \beta}>0 .{ }^{14}$ Hence, the technology structure exhibits diseconomies of scale and the more stringent are the requirements, the more difficult it is to increase the production. 
Using equations (14) and (15), the optimal level of standards chosen by farmers and processors are summarized in table 3 .

Table 3 is inserted here.

The result suggests that, in this particular case, a stringent standard is always preferred by farmers, while it is preferred by processors only in the oligopsony case. The stringency of the standard chosen by farmers increases with the demand parameter $b$ and the number of farmers $n$. Hence, a higher standard will be preferred by farmers when the demand becomes more inelastic (the larger is $b$ ). Moreover, when the number of farmers increases, the supply curve becomes flatter, that is, more elastic. Hence, farmers will have more incentive to increase the strengengy of the standard. This incentive will be enhanced under oligopoly competition, but reduced under oligopsony competition. It reaches the highest level under pure monopoly (i.e., $\beta=2 b n$ ) and the lowest level under pure monopsony $\left(\beta=\frac{1}{2} b n\right) .{ }^{15}$ Under pure monopoly competition, the price of the commodity is the highest and more rent can be transferred to farmers by increasing the strengency of the standard. Thus, in almost all cases, except for the oligopsony case, farmers and processors have conflicting interests in choosing the production standard.

The result will be different if the demand for the final product is captured by a constant elasticity function $\left(a x^{-\frac{1}{\varepsilon_{d}}}\right)$. In this case, the elasticity of demand plays a determining role. It can be shown that farmers prefer a higher level of standard if and only if the demand is inelastic, so that $\varepsilon_{d}<1$, while they prefer the lowest standard for an elastic demand $\left(\varepsilon_{d}>1\right)$. Processors will have the same incentive as farmers if they have only oligopsony power or if they have both oligopoly and oligopsony power. However, they prefer the lowest standard if they are in perfect competition or if they have only oligopoly power.

The previous result can be applied to identify some implications about the quality provision in the agri-food sector. In the context that the production procedure is not directly perceived by consumers so that the product quality does not reflect a high willingness to 
pay, our results show that it is still possible that players in the agri-food supply chain have incentives to implement a stringent production standard. Such incentives depend on three main factors: the way the standard modifies the production technology, the demand characteristics of the final product, and the competition behavior of processors.

First, most food industries exhibit nonconstant returns to scale (Bhuyan and Lopez 1997), which makes our analysis relevant when assuming an increasing marginal cost function and not a constant marginal cost function. In this setting, it is more likely for a stringent standard to be implemented if the standard introduces more diseconomies of scale in production. This will be the case if the marginal cost of increasing the level of the standard exceeds the average cost of increasing the level of the standard. This feature can be found in many agricultural production chains. As noted by Merel and Sexton (2011), for example, this occurs when increasing the stringency of the standard generates a greater additional cost compared to the cost of the prime acreage (crop production, for instance). ${ }^{16}$ This is more likely for those standards imposed on production in less-favored rural areas, in mountain areas, and in the most remote regions, where the farming sector accounts for a significant part of the economy and production costs are high. The EU system of PDO and PGI corresponds to this case. According to European Union (2012), the system aims to complement rural development and provide market and income support for producers in areas in which the farming sector is of greater economic importance and, especially, in disadvantaged areas. Thus, our result that a more stringent standard is more likely to favor farmers operating in circumstances in which there are greater diseconomies of scale in production, and provides support to the promotion of the PDO/PGI system by the EU authority.

Second, the stringency of the standard depends on demand characteristics and, more particularly, on demand elasticity. One of the main characteristics of food markets is the inelasticity of demand to price changes (Bhuyan and Lopez 1997 for US markets and Moro and Sckokai 2000 for European markets). A recent survey on price elasticity of demand has been conducted for the main food markets (Andreyeva, Long, and Brownell 2010) and 
found that price elasticities were below 1, ranging from -0.27 (eggs) to -0.8 (soft drinks). This suggests that our findings may well apply to food markets as they exhibit relatively low demand elasticity.

These two features of agricultural and food markets suggest that farmers may have incentives to set stringent standards. The magnitude of the stringency will depend on the type of competition in food markets. Many food-processing industries involve relatively few processors who purchase a raw farm product from many producers, transform it into a final product, and sell it to a large number of consumers. Food processors can thus have potential oligopsony power in their input procurement markets and oligopoly power in the final commodity market. Many examples of oligopoly and oligopsony power can be found in the empirical literature on food markets in the EU and in the US. For instance, Bhuyan and Lopez (1997) show that food and tobacco industries exert statistically significant degrees of oligopoly power. Chen and Lent (1992) find that oligopsony power exists particularly in primary agricultural markets. We can thus presume that if oligopsony power is at stake, this may compensate the oligopoly impact, such that the standard should not be too high. In this situation, the standard should still be higher than the minimum level because processors will also have an incentive to increase the level of the standard.

Finally, the present analysis assumes that the stringency of the standard does not affect the final demand for the good when it is set above the minimum level. This enables us to isolate cost effects and understand why we do observe stringent standards while the true level of the standard is not always observed by consumers. However, when this assumption is relaxed such that consumers are able to perceive the increase in the standard and are willing to pay for it, an additional effect, the demand shifting effect, as noticed in Merel and Sexton (2011) and Hamilton (1999), is at stake for the standard choice. This additional effect reinforces the incentive of both farmers and processors to impose a stringent standard as it increases the total supply chain's profit. However, by increasing the level of the standard, farmers may be able to extract more surplus from the implementation of the standard to 
the detriment of processors. This is particularly the case when the standard imposes greater diseconomies of scale in production and thus rotates the aggregate supply curve upwards. The standard stringency, as in the previous case, may thus be used as a device to transfer some of the additional rent to farmers.

This can be illustrated in figure 3 in the oligopoly case when an increase in the strengency of the standard generates a parallel upward shift of the demand curve. The two panels correspond to the cases where the supply is rotated upward with the standard (panel (a)) and where the standard has no effect on the supply curve (panel (b)), respectively. It can be seen from the left panel (a) that when the standard is increased from $\beta_{1}$ to $\beta_{2}$, the farmers' price increases from $w_{1}$ to $w_{2}$ and their surplus increases from $n \pi^{f}\left(\beta_{1}\right)$ (the grey triangle) to $n \pi^{f}\left(\beta_{2}\right)$ (the black triangle). Meanwhile, the processors' price increases from $p_{1}$ to $p_{2}$ and their surplus increases from $n \pi^{p}\left(\beta_{1}\right)$ (the grey rectangle) to $n \pi^{p}\left(\beta_{2}\right)$ (the black rectangle). Thus, the total industry surplus increases. Similarly, if the standard has no rotation effect

on the supply curve (hence, the supply curve remains unchanged $c_{q}\left(\frac{X}{n}, \beta_{1}\right)=c_{q}\left(\frac{X}{n}, \beta_{2}\right)$ ), the right panel (b) shows that both farmers' and processors' profits increase with $\beta$ shifting the demand curve upwards. However, comparing the two cases, the incremental increase in farmers' price (from $w_{1}$ to $w_{2}$ ) is lower in the absence of the supply rotation effect. Hence, without the rotation effect, the increase of farmers' profit would be smaller (the black triangle is smaller in panel (b) than in panel (a)), while processors' profits would be larger (the black rectangle is larger in panel (b)). In other words, although the industry surplus is larger if demand increases with the implementation of standards, farmers benefit more only in the case when the standard can rotate the supply curve upwards.

Figure 3 is inserted here.

\section{Concluding remarks}

This paper investigates the choice of production standard within a vertical production chain, taking into account the competition structure of the market. In a context in which raising 
the production standard cannot lead to a direct price premium to consumers, we derive the condition under which producers and processing firms in the production chain are willing to impose a stringent production standard. We find that the condition depends on the final demand and cost structure of upstream producers. In particular, when the production requirement imposes greater diseconomies of scale in production and when the final market demand is inelastic, it is more likely that the upstream producers prefer a more stringent production standard.

Our results are particularly relevant to B2B standards but also to standards that involve the interaction between both the public and private sectors. The EU PDO/PGI system, which was created by the EU public authority to promote and protect food products, is an example of such standard, but the certified production standards are typically developed by private producer/processor organizations (Merel and Sexton 2011; Lence et al. 2007). The question is which group in the supply chain really benefits from the public promotion of the standards. Our results provide support to the EU PGI system in that farmers do benefit from the stringent production requirement, even if doing so will not bring about a direct price increase for their product.

The model is developed under some assumptions, which deserve further extension. First, we assume that only upstream farmers bear the cost of an increasingly stringent standard, but further work could involve extending our results to the case in which processors are also involved in costly production control. Second, in our model, the certification cost does not play a role because we assume no free entry. This gives us scope to analyze the impact of the certification cost on the incentive of farmers and processors to join the standard. Third, we assume that farmers and processors are homogenous in the market, whereas, in practice, they are often heterogenous in productivity, size, geographical areas, etc. It is thus worthwhile to introduce some heterogenous aspects, which may affect their participation in developing and adopting the standards. Finally, the model assume that farmers and processors trade with 
a uniform price. It will be interesting to investigate the contractual relationship between farmers and processors. 


\section{Notes}

${ }^{1}$ Loureiro and McCluskey (2000) find that the price premium for GI is higher for medium quality products than for the highest quality ones. Hassan, Monier-Dilhan, and Orozco (2011) show that PDOs are more price-elastic than standard products, suggesting that PDOs do not necessarily represent the high quality product, and hence the PDO suppliers cannot raise prices without suffering from reductions in demand.

${ }^{2}$ The standards are initiated and adopted by farmers and grower associations and then extend to the whole supply chain (see Garcia 2007).

${ }^{3}$ We assume that there is no free entry in both the input and the final product markets. This corresponds to the cases in which farmers and processors operate in a limited area, like a mountain region, in which it is difficult for producers from outside the region to enter.

${ }^{4}$ Here, the downstream buyers are food processors. The framework can also be applied, however, to B2B standards involving farmers and retailers. In the remainder of the paper, we refer to food processors as being either processors or retailers in the downstream market.

5 The demand function is in line with the quasi-linear consumer utility function in Lence et al. (2007): $U(X, X N u m)=u(X)+N u m$ where $X$ and $N u m$ denote, respectively, aggregate consumption of the good with which the standard is concerned and a numéraire good.

6 Such cost function can take the form of $c(q, \beta)=h(q)+g(\beta)$. This is the case when the production standard is not linked to production activities (for instance, the certification costs).

7 See Section 6 for further discussion on technology.

8 In a vertical differentiation model, Merel and Sexton (2011) assume that consumers are heterogenous, with the taste distribution following a beta density function, and that the 
producers' cost function is in the form of $C(q, \beta)=c q^{1+a} \beta^{1+b}$ (where $c, a$, and $b$ are positive parameters).

${ }^{9}$ Note that when the standard introduces greater diseconomies of scale in production (the higher is the level of $\eta$ ), the aggregate supply becomes much more inelastic (hence, the smaller is $\boldsymbol{\varepsilon}_{s}$ ). Thus, it will be less likely for condition (8) to hold.

10 As in Sexton and Lavoie (2001), condition (10) can be rearranged in the form of the Lerner index: $L \equiv \frac{p-w}{p}=\frac{1}{m}\left(\frac{1}{\varepsilon_{d}}+\frac{w}{p} \frac{1}{\varepsilon_{s}}\right)=\frac{\varepsilon_{s} / \varepsilon_{d}+1}{m \varepsilon_{s}+1}$. This condition can be seen as the "adjusted" inverse elasticity rule, which takes into account the number of firms as well as upstream competition. Under the condition $\varepsilon_{d}>\frac{1}{m}$, the solution exists and is such that the less elastic the demand for the final product and the less elastic the supply of the input, the more processing firms can exercise their oligopoly and oligopsony power.

${ }^{11}$ Under the Cournot stability condition, $\frac{1}{m}\left(p^{\prime}+X p^{\prime \prime}\right)<0$, which holds if the demand is not too convex.

12 The condition holds if the supply is not too concave.

13 Taking the derivative of the right-hand side terms of the farmers' profit condition (2nd line in 2nd column) with respect to $m$ gives: $\frac{\partial R H S}{\partial m}=\frac{1+\varepsilon_{d}\left(1-V_{d}\right)}{\varepsilon_{s}\left(m+1-V_{d}\right)}$. In order to ensure the uniqueness of the solution, we assume that the demand is not too convex, so that $1-V_{d}>0$. Hence, the right-hand side of the condition increases with $m$.

14 The cost function can be generalized to $f(\beta) q^{2}$, which will not change the result as long as $f^{\prime}(\beta)>0$.

${ }^{15}$ Note that in this specific case, we obtain the same level of $\beta$ for farmers under perfect competition and the case with both oligopoly and oligopsony power.

${ }^{16}$ For a more detailed discussion on this issue, see Merel and Sexton (2011). 


\section{References}

Akerlof, G. 1970. "The Market for "Lemons": Quality Uncertainty and the Market Mechanism." Quarterly Journal of Economics 84:488-500.

Anania, G., and R. Nistico. 2004. "Public Regulation as a Substitute for Trust in Quality Food Markets: What if the Trust Substitute Cannot be Fully Trusted?" Journal of Institutional and Theoretical Economics 160:681-701.

Andreyeva, T., M.W. Long, and K.D. Brownell. 2010. "The Impact of Food Prices on Consumption: A Systematic Review of Research on the Price Elasticity of Demand for Food." American Journal of Public Health 100:216-222.

Antle, J.M. 2001. "Economic Analysis of Food Safety." Handbook of Agricultural Economics 1:1083-1136.

Beghin, J.C., and J.C. Bureau. 2001. Quantification of Sanitary, Phytosanitary, and Technical Barriers to Trade for Trade Policy Analysis. Center for Agricultural and Rural Development, Iowa State University.

Bhuyan, S., and R.A. Lopez. 1997. "Oligopoly Power in the Food and Tobacco Industries." American Journal of Agricultural Economics 79:1035-1043.

Bouamra-Mechemache, Z., and J. Chaaban. 2010. "Determinants of Adoption of Protected Designation of Origin Label: Evidence from the French Brie Cheese Industry." Journal of Agricultural Economics 61:225-239.

Bredahl, M.E., J.R. Northen, A. Boecker, and M.A. Normile. 2001. "Consumer Demand Sparks the Growth of Quality Assurance Schemes in the European Food Sector." Working paper, Changing Structure of the Global Food Consumption and Trade. Market and Trade Economics Division, Economic Research Service, US Department of Agriculture, Agriculture and Trade Report. WRS-01-1, May.

Carriquiry, M., and B.A. Babcock. 2007. "Reputations, Market Structure, and the Choice of Quality Assurance Systems in the Food Industry." American Journal of Agricultural Economics 89:12-23. 
Chen, Z., and R. Lent. 1992. "Supply Analysis in an Oligopsony Model." American Journal of Agricultural Economics 74:973-979.

Coibion, O., L. Einav, and J. Hallak. 2007. "Equilibrium Demand Elasticities across Quality Segments." International Journal of Industrial Organization 25:13-30.

Crampes, C., and A. Hollander. 1995. "Duopoly and Quality Standards." European Economic Review 39:71-82.

de Roest, K., and A. Menghi. 2000. "Reconsidering "Traditional" Food: The Case of Parmigiano Reggiano Cheese." Sociologia Ruralis 40:439-451.

Deselnicu, O., M. Costanigro, D.M. Souza Monteiro, and D.D. Thilmany. 2011. "What Determines the Success of a Geographical Indication? A Price-based Meta-Analysis for GIs In Food Products." 2011 Annual Meeting, July 24-26, 2011, Pittsburgh, Pennsylvania No. 104000, Agricultural and Applied Economics Association.

European Union. 2012. "Regulation on Quality Schemes for Agricultural Products and Foodstuffs." Official Journal of the European Union 1151/2012:L 343/1 - L 343/29.

Fritz, M., and G. Schiefer. 2009. "Tracking, Tracing, and Business Process Interests in Food Commodities: A Multi-Level Decision Complexity." International Journal of Production Economics 117:317-329.

Fulponi, L. 2006. "Private Voluntary Standards in the Food System: The Perspective of Major Food Retailers in OECD Countries." Food Policy 31:1-13.

Garcia, M. 2007. "Economic Analysis of Food Quality Assurance Schemes, the Red Tractor Scheme." Working paper, European Commission, Directorate-General JRC Joint Research Centre, Institute for Prospective Technological Studies (Seville) Sustainability in Agriculture, Food and Health.

Gardner, B. 2003. "U.S. Food Quality Standards: Fix for Market Failure or Costly Anachronism?" American Journal of Agricultural Economics 85:725-730.

Garella, P.G., and E. Petrakis. 2008. "Minimum Quality Standards and Consumers' Information." Economic Theory 36:283-302. 
Giraud-Heraud, E., A. Hammoudi, R. Hoffmann, and L.G. Soler. 2012. "Joint Private Safety Standards and Vertical Relationships in Food Retailing." Journal of Economics 83 Management Strategy 21:179-212.

Hackner, J. 2000. "A Note on Price and Quantity Competition in Differentiated Oligopolies." Journal of Economic Theory 93:233-239.

Hamilton, S.F. 1999. "Demand Shifts and Market Structure in Free-Entry Oligopoly Equilibria." International Journal of Industrial Organization 17:259-275.

Hamilton, S.F., and D. Sunding. 1998. "Returns to Public Investments in Agriculture with Imperfect Downstream Competition." American Journal of Agricultural Economics 80:830-838.

Hamilton, S.F., and D.L. Sunding. 1997. "The Effect of Farm Supply Shifts on Concentration and Market Power in the Food Processing Sector." American Journal of Agricultural Economics 79:524-531.

Hammoudi, A., R. Hoffmann, and Y. Surry. 2009. "Food Safety Standards and Agri-Food Supply Chains: An Introductory Overview." European Review of Agricultural Economics 36:469-478.

Hassan, D., S. Monier-Dilhan, and V. Orozco. 2011. "Measuring Consumers' Attachment to Geographical Indications." Journal of Agricultural $\& 3$ Food Industrial Organization 9:5.

Hatanaka, M., C. Bain, and L. Busch. 2005. "Third-Party Certification in the Global AgriFood System." Food Policy 30:354-369.

Hayes, D.J., S.H. Lence, and A. Stoppa. 2004. "Farmer-Owned Brands." Agribusiness 20:269285.

Henson, S., and J. Caswell. 1999. "Food Safety Regulation: An Overview of Contemporary Issues." Food Policy 24:589-603.

Henson, S., and M. Heasman. 1998. "Food Safety Regulation and the Firm: Understanding the Compliance Process." Food Policy 23:9-23. 
Henson, S., and J. Humphrey. 2009. "The Impacts of Private Food Safety Standards on the Food Chain and on Public Standard-Setting Processes." Working paper, Joint FAO/WHO Food Standards Programme, Codex Alimentarius Commission, ALINORM 09/32/9D-Part II.

Henson, S., and T. Reardon. 2005. "Private Agri-Food Standards: Implications for Food Policy and the Agri-Food System." Food Policy 30:241-253.

Josling, T. 2006. "The War on Terroir: Geographical Indications as a Transatlantic Trade Conflict." Journal of Agricultural Economics 57:337-363.

Krieger, S., and G. Schiefer. 2004. "Quality Management Schemes in Europe and Beyond." In AFITA/WCCA Joint Congress on ITIN Agriculture.

Lence, S., S. Marette, D. Hayes, and W. Foster. 2007. "Collective Marketing Arrangements for Geographically Differentiated Agricultural Products: Welfare Impacts and Policy Implications." American Journal of Agricultural Economics 89:947 - 963.

Loureiro, M., and J. McCluskey. 2000. "Assessing Consumer Response to Protected Geographical Identification Labeling." Agribusiness 16:309-320.

Manning, L., R. Baines, and S. Chadd. 2007. "Quality Assurance: A Study of the Primary Poultry Producers' Perspective." British Food Journal 109:291-304.

Marette, S. 2005. "The Collective-Quality Promotion in the Agribusiness Sector: An Overview." Midwest Agribusiness Trade Research and Information Center (MATRIC) Publications No. 05-wp406, Midwest Agribusiness Trade Research and Information Center (MATRIC) at Iowa State University, Oct.

-. 2007. "Minimum Safety Standard, Consumers' Information and Competition." Journal of Regulatory Economics 32:259-285.

—. 2008. "Standards and Labels." Economics Bulletin 12:1-7.

Marette, S., R. Clemens, and B. Babcock. 2008. "Recent International and Regulatory Decisions about Geographical Indications." Agribusiness 24:453-472. 
Marette, S., and J.M. Crespi. 2003. "Can Quality Certification Lead to Stable Cartels?" Review of Industrial Organization 23:43-64.

Marette, S., J.M. Crespi, and A. Schiavina. 1999. "The Role of Common Labelling in a Context of Asymmetric Information." European Review of Agricultural Economics 26:167178.

McCluskey, J. 2007. "Public and Private Food Quality Standards: Recent Trends and Strategic Incentives." Global supply chains, standards, and the poor, ed.by Johan F.M. Swinnen $3: 19-25$.

McCluskey, J.J., and J.A. Winfree. 2009. "Pre-Empting Public Regulation with Private Food Quality Standards.” European Review of Agricultural Economics 36:525-539.

Merel, P., and R.J. Sexton. 2011. "Will Geographical Indications Supply Excessive Quality?" European Review of Agricultural Economics 39(4):567-587.

Merel, P.R. 2009. "On the Deadweight Cost of Production Requirements for Geographically Differentiated Agricultural Products." American Journal of Agricultural Economics 91:642-655.

Moro, D., and P. Sckokai. 2000. "Heterogeneous Preferences in Household Food Consumption in Italy." European Review of Agricultural Economics 27:305-323.

Moschini, G., L. Menapace, and D. Pick. 2008. "Geographical Indications and the Competitive Provision of Quality in Agricultural Markets." American Journal of Agricultural Economics 90:794-812.

Ronnen, U. 1991. "Minimum Quality Standards, Fixed Costs, and Competition." The RAND Journal of Economics 22:490-504.

Scarpa, R., G. Philippidis, and F. Spalatro. 2005. "Product-Country Images and Preference Heterogeneity for Mediterranean Food Products: A Discrete Choice Framework." Agribusiness 21:329-349.

Sexton, R.J., and N. Lavoie. 2001. "Food Processing and Distribution: An Industrial Organization Approach." In B. L. Gardner and G. C. Rausser, eds. Handbook of Agricultural 
Economics. Elsevier, vol. 1, Part 2, chap. 15, 1st ed., pp. 863-932.

Trienekens, J., and P. Zuurbier. 2008. "Quality and Safety Standards in the Food Industry, Developments and Challenges." International Journal of Production Economics 113:107122.

Tunçer, B. 2001. "From Farm to Fork? Means of Assuring Food Quality." Unpublished, MSc dissertation, IIEE, Lund University.

von Schlippenbach, V., and I. Teichmann. 2012. "The Strategic Use of Private Quality Standards in Food Supply Chains." American Journal of Agricultural Economics 94:1189-1201. Winfree, J.A., and J.J. McCluskey. 2005. "Collective Reputation and Quality." American Journal of Agricultural Economics 87:206-213. 


\section{Figures}

Figure 1. Impact of the standard $\beta$ on farmers' profit under perfect competition

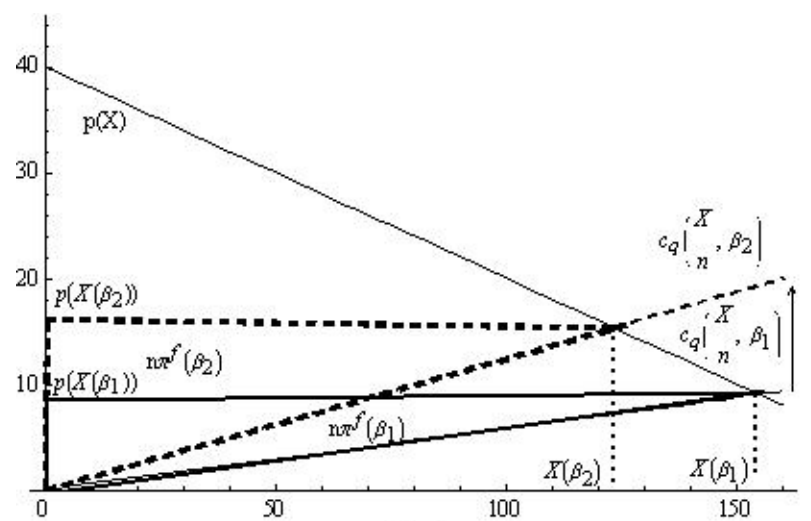

(a)

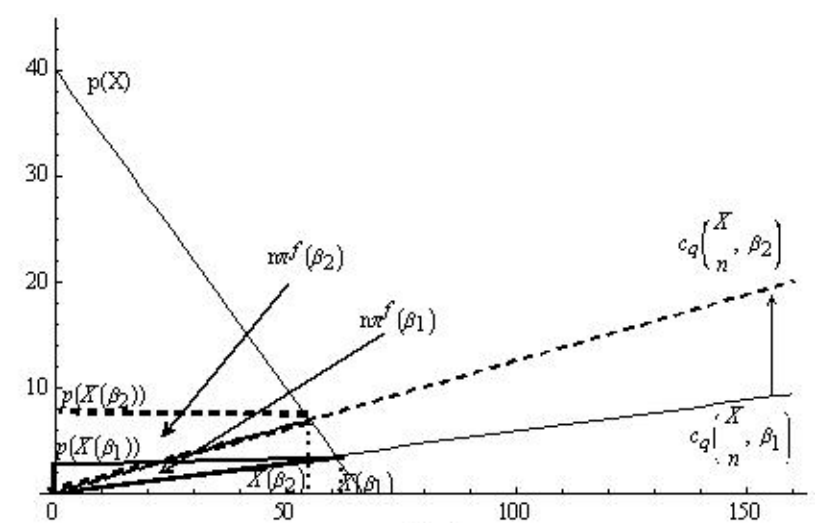

(b) 
Figure 2. Conflicting incentives in choosing a standard
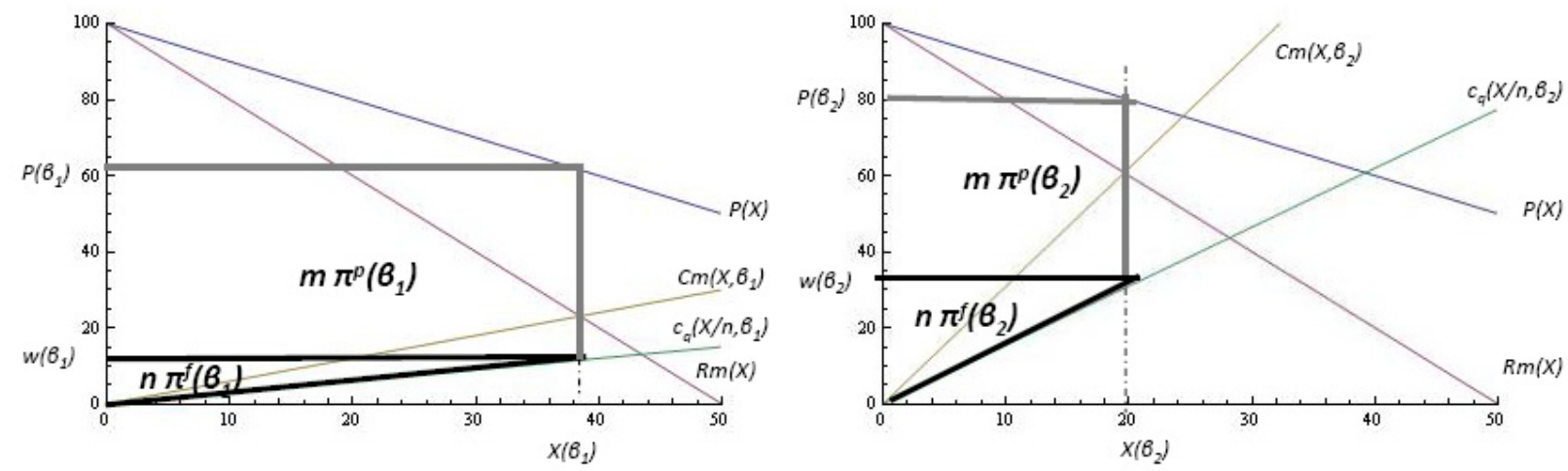
Figure 3. Profit change when $\beta$ increases the demand for the final product

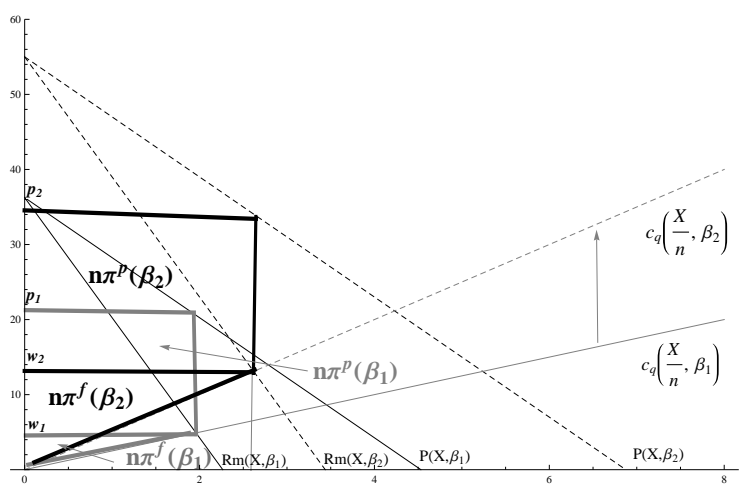

(a) Supply curve rotates upward with $\beta$

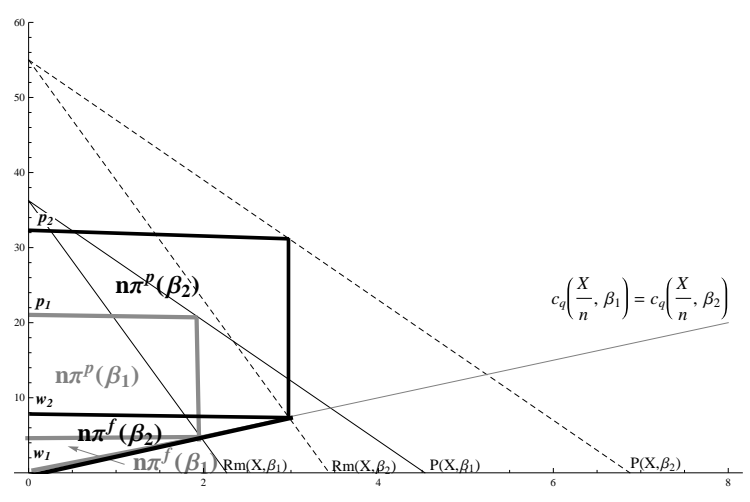

(b) No supply-rotation effect 


\section{Tables}

Table 2. Conditions of setting a higher standard under different market structures

\begin{tabular}{l|lll} 
& Perfect Competition & Oligopoly & Oligopsony \\
\hline $\begin{array}{l}\text { Farmers: } \beta^{f}> \\
0 \text { iff }\end{array}$ & $\eta>1+\frac{\varepsilon_{d}}{\varepsilon_{s}}$ & $\eta>1+\frac{m \varepsilon_{d}-1}{\varepsilon_{s}\left(m+1-V_{d}\right)}$ & $\eta>1+\frac{\mu+m}{\frac{m \varepsilon_{s}+1}{\varepsilon_{d}}+1+V_{s}-\mu}$ \\
$\begin{array}{l}\text { Processors: } \\
\beta^{p}>0 \text { iff }\end{array}$ & $\beta^{p}=0$ & $\beta^{p}=0$ & $\mu>\frac{m\left(2+V_{s}\right)}{\frac{m \varepsilon_{s}+1}{\varepsilon_{d}}+m-1}$ \\
\hline
\end{tabular}


Table 3. Choice of quality standard-case of linear demand and supply functions

\begin{tabular}{l|lccccc} 
& $\begin{array}{l}\text { Perfect } \\
\text { Competi- } \\
\text { tion }\end{array}$ & Monopoly & Oligopoly & Monopsony & Oligopsony & Both \\
\hline Farmers & $\beta^{f}=b n$ & $\beta^{f}=2 b n$ & $\beta^{f}=\frac{1+m}{m} b n$ & $\beta^{f}=\frac{1}{2} b n$ & $\beta^{f}=\frac{m}{1+m} b n$ & $\beta^{f}=b n$ \\
Processors & $\pi^{p=0}$ & $\beta^{p}=0$ & $\beta^{p}=0$ & $\beta^{p}=\frac{1}{2} b n$ & $\beta^{p}=\frac{m}{1+m} b n$ & $\beta^{p}=0$ \\
\hline
\end{tabular}

